\title{
Estrogen Receptor Alpha Binding to ERE is Required for Full Tlr7- and Tlr9-Induced Inflammation
}

\author{
Melissa A Cunningham ${ }^{1,2 *}$, Jena R Wirth ${ }^{1}$, Osama Naga ${ }^{1}$, Jackie Eudaly ${ }^{1}$ and \\ Gary S Gilkeson ${ }^{1}$ \\ ${ }^{1}$ Division of Rheumatology and Immunology, Medical University of South Carolina, USA \\ ${ }^{2}$ Ralph H. Johnson Veterans Affairs Hospital, Charleston, South Carolina, USA
}

Received: November 27, 2013; Accepted: December 17, 2013; Published: January 20, 2014

*Corresponding author: Melissa A Cunningham, 96 Jonathan Lucas Street, Suite 814, MSC637, Charleston, SC 29425, USA, Tel: 843-789-6799; Fax: 843-876-5131; E-mail: cunnima@musc.edu

\begin{abstract}
We previously found that a maximum innate inflammatory response induced by stimulation of Toll-like Receptors (TLRs) 3, 7 and 9 requires $\mathrm{ER} \alpha$, but does not require estrogen in multiple cell types from both control and lupus-prone mice. Given the estrogenindependence, we hypothesized that ER $\alpha$ mediates TLR signaling by tethering to, and enhancing, the activity of downstream transcription factors such as $N F \kappa B$, rather than acting classically by binding EREs on target genes. To investigate the mechanism of ER $\alpha$ impact on TLR signaling, we utilized mice with a knock-in ER $\alpha$ mutant that is unable to bind ERE. After stimulation with TLR ligands, both ex vivo spleen cells and Bone Marrow-Derived Dendritic Cells (BM-DCs) isolated from mutant ER $\alpha$ ("KIKO") mice produced significantly less IL-6 compared with cells from Wild-Type (WT) littermates. These results suggest that ER $\alpha$ modulation of TLR signaling does indeed require ERE binding for its effect on the innate immune response.
\end{abstract}

Keywords: (ER $\alpha)$; (TLRs); (DCs)

\section{Abbreviations}

ER $\alpha$ : Estrogen receptor alpha; TLRs: Toll-like receptors; DCs: Dendritic cells

\section{Introduction}

One of the more profound features of lupus is that females have a 9:1 prevalence of disease over males. The cause of the sex bias in lupus is likely multifactorial, including differences in the sex chromosomes, sex hormones and their receptors. Although estrogen acts primarily via its receptors, estrogen receptor alpha and beta $(E R \alpha / E R \beta)$, estrogen can also act through non-receptor mediated mechanisms. Interestingly, there is growing evidence that ERs can mediate physiologic functions independent of estrogen. We previously showed that an optimal inflammatory response by TLRs is dependent on ER $\alpha$, but independent of estrogen in multiple cell types. B cells and DCs derived from both B6 ER $\alpha \mathrm{KO}$ and lupus-prone ER $\alpha \mathrm{KO}$ mice had a significantly blunted response to TLR 7 and 9 ligands [1]. These data suggest that ER $\alpha$ modulation of TLR signaling may play a role in lupus pathogenesis, and appears to be independent of estrogen effects.
Based on these findings, we hypothesized that ER $\alpha$ mediates TLR signaling by a genomic, but non-classical mechanism, i.e. by tethering to and enhancing the activity of downstream transcription factors such as $\mathrm{NFKB}$, thereby altering the innate immune response and exacerbating inflammation. An alternative mechanism to explain this ligand independence is activation via kinase cascades including MAPKs (rapid signaling pathway). To investigate the mechanism of ER $\alpha$ impact on TLR signaling, we utilized mice with a knock-in ER $\alpha$ mutant ("KIKO") that is unable to bind ERE, but otherwise functions normally with regard to ligand binding, activation, etc [2]. Female mice that carry a single copy of this non-classical ER $\alpha$ knock-in mutation are infertile due to severe ovarian and uterine defects, [3] but their immune phenotype is not known.

In this communication we show that both ex vivo spleen cells and bone-marrow-derived dendritic cells (BM-DCs) from KIKO mice (ER $\alpha$ DNA-binding mutant mice) behave similarly to ER $\alpha$ KO mice in that TLR-stimulated endpoints are blunted. We previously showed that multiple TLR-induced cytokines are impacted by ER $\alpha$ IL-6, MCP-1, IL-23, IL-17 among others. In this study we looked at IL-6, which has multiple pro-inflammatory effects and is a potent activator of the NFKB pathway. IL-6 is known to play a critical role in the immunopathology of SLE in both humans and mice (contributes to B cell hyperactivity and differentiation of $\mathrm{T}$ cells into effector cells, including Th17 cells) [4-6]. Blocking IL-6 in mouse models of SLE significantly improves disease [7]. Herein we show that DNA binding of ER $\alpha$ is required for TLR-induced IL- 6 production in murine immune cells. These findings suggest that ERE binding is indeed required for ER $\alpha$ modulation of TLR-induced inflammation, despite the lack of estrogen in the system, and future studies will confirm this result in a lupus mouse model.

\section{Materials and Methods \\ Mice}

Female NERKI (ER $\alpha$ DNA-binding mutant) and Ex3a (ERanull) mice on the C57BL/6/129 background (kind gift of Ken Korach, NIEHS, NC) were crossed to obtain the "KIKO" mouse 
as previously described. All mice were maintained at the Ralph H. Johnson VAMC Animal Care Facility (Charleston, SC) using Institutional Animal Care and Use Committee approved protocols.

\section{Generation of BMDCs and Spleen cells}

Bone marrow-derived DCs were generated using a modified version of the protocol originally described by Inaba et al. [8], without lymphocyte depletion. Briefly, equal numbers of BM cells from WT and KIKO mice were suspended in complete RPMI supplemented with $20 \mathrm{ng} / \mathrm{mL}$ murine GM-CSF and 20ng/mL murine IL-4 (R\&D systems, Minneapolis, MN) and cultured in T75 flasks at $1 \times 10^{6}$ cells $/ \mathrm{ml}\left(\sim 20 \times 10^{6} /\right.$ flask $)$ for 7 days. BMDCs were harvested from flasks, counted, and re-plated in 6-well plates at $1 \times 10^{6}$ cells $/ \mathrm{ml}\left(4 \times 10^{6} /\right.$ well) for $18 \mathrm{~h}$. For spleen cells, mice were sacrificed and spleens harvested and kept in ice-cold RPMI. Spleens were processed and subjected to red blood cell lysis. Cells were washed twice in cold RPMI before being counted and cultured in 12 - or 6-well plates at $1 \times 10^{6}$ cells $/ \mathrm{ml}\left(2-4 \times 10^{6}\right)$ well) for $18 \mathrm{~h}$.

\section{Treatment of DCs with TLR agonists}

BM-DCs were harvested on day 7 from BM cultures as described above, seeded at $1 \times 10^{6}$ cells/ml into 6- or 12 -well plates in estrogen-free phenol red-free RPMI with $10 \%$ charcoaldextran-stripped FCS and treated with vehicle or TLR agonist: loxoribine (TLR7/8 agonist; 50-200 $\mu$ mol, Sigma-Aldrich, St. Louis, MO), or CpG DNA (TLR9 agonist; $1 \mu \mathrm{g} / \mathrm{ml}$, Hycult Biotech, Canton, MA) for $18 \mathrm{~h}$.

\section{Cytokine Release Assay}

Cytokine release by DCs and spleen cells was determined by culturing $2 \times 10^{6} / \mathrm{mL}$ cells with either vehicle or TLR agonist. After $18 \mathrm{~h}$, culture supernatants were harvested and cytokine (IL6) concentrations were measured by sandwich ELISA as per the manufacturer's protocol (eBioscience, Inc., San Diego, CA) using a micro-plate luminometer (Thermo Scientific Multiskan Ascent).
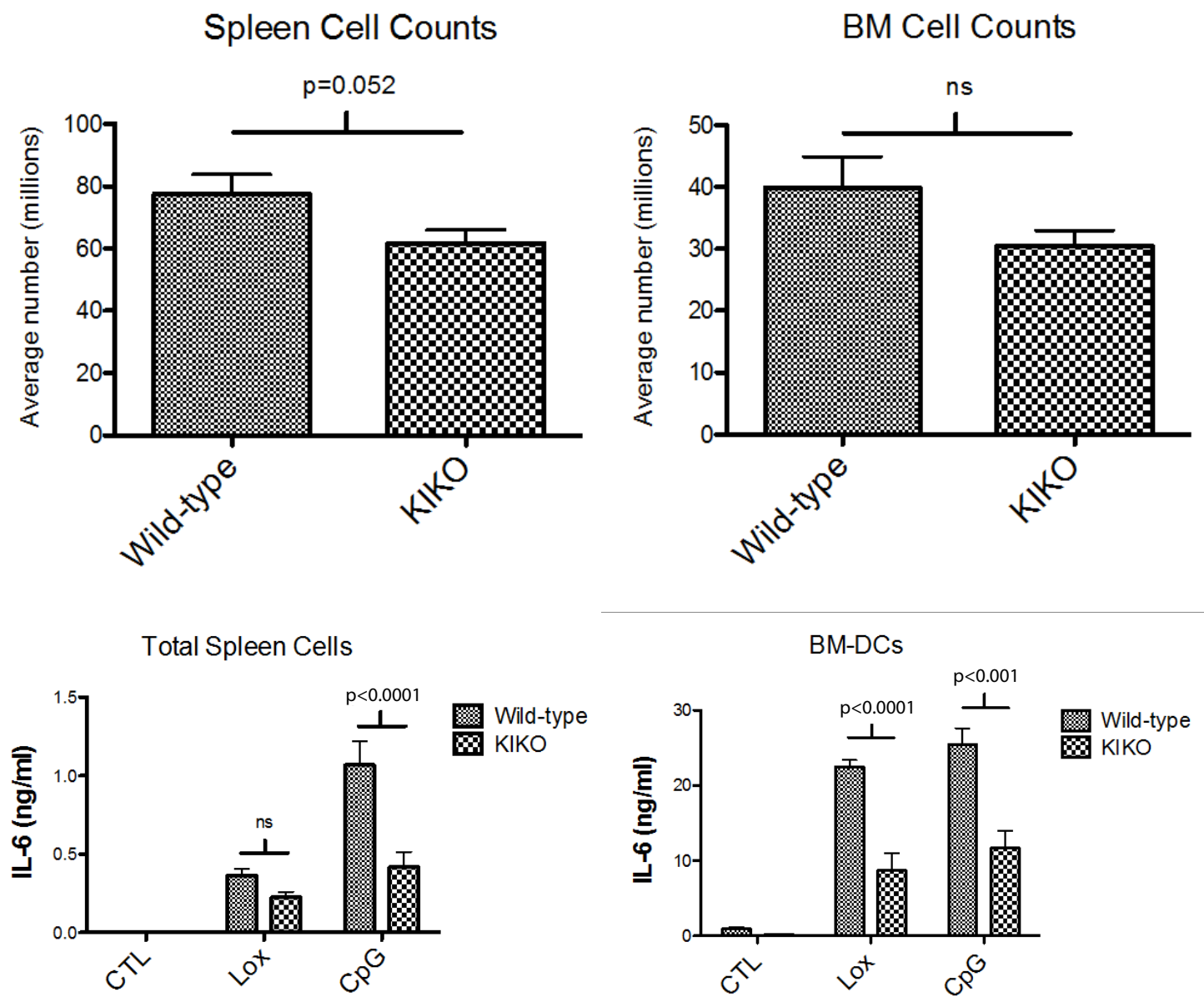

Figure 1: $(A)$ Twenty mice $(n=8$ WT, $n=12$ KIKO) were sacrificed at 18 weeks. Spleens from KIKO mice were smaller and there was a significant difference in spleen cell counts between WT and KIKO mice. In a subset of animals ( $\mathrm{n}=4 \mathrm{WT}, \mathrm{n}=5 \mathrm{KIKO}$ ), femurs were harvested and bone marrow cells were counted. There was a trend toward reduced numbers in the KIKO mice that did not reach significance. (B) Ex vivo spleen cells (n $=4 \mathrm{WT}$, $\mathrm{n}=7 \mathrm{KIKO})$ and cultured BM-DCs ( $=4 \mathrm{WT}, \mathrm{n}=5 \mathrm{KIKO})$ were stimulated overnight $(18 \mathrm{~h})$ with $200 \mu \mathrm{mol}$ loxoribine (TLR 7 ligand) or $1 \mu \mathrm{g} / \mathrm{mol} \mathrm{CpG}$ DNA (TLR9 ligand) under estrogen-free media conditions. TLR stimulation resulted in increased IL-6 production that was significantly decreased in media from KIKO mice compared to wild-type mice. 


\section{Results}

Spleen counts are significantly reduced in ER $\mathrm{DNA}$ binding domain mutant mice ("KIKO") compared with wild-type mice

Twenty C57BL/ 6 mice (8 WT and 12 KIKO) were sacrificed at 18 weeks. Spleen cells were isolated and counted. Spleens from KIKO mice were smaller and there was a significant difference in spleen cell counts between WT and KIKO mice (Figure 1A). This result aligns with previously published studies demonstrating a critical role for estradiol and ER $\alpha$ in immune organ development (spleen, thymus) as well as murine DC development [9-13]. In a subset of animals (4 WT and 5 KIKO) femurs were harvested and bone marrow cells were counted. There was a trend towards reduced number of cells in the KIKO mice, however it did not reach significance.

TLR7- and 9-induced IL-6 production by ex vivo spleen cells and BM-DCs is significantly reduced in KIKO mice

We examined IL-6 production by spleen cells following TLR stimulation. Spleens were harvested and spleen cells were stimulated overnight (18h) with loxoribine (TLR 7 ligand) or CpG DNA (TLR9 ligand) under estrogen-free media conditions. Both TLR7 and TLR9 stimulation resulted in significantly increased levels of IL-6 production by spleen cells (Figure 1), however, IL-6 produced by cells from KIKO animals was significantly reduced compared to wild-type mice, as measured by ELISA. This result suggests that TLR-induced inflammatory cytokine production is modulated by ER $\alpha$ and requires direct ERE binding, despite the absence of estrogen.

DCs express high levels of TLRs and are key mediators of the innate immune response. We isolated bone marrow hematopoietic cells from WT or KIKO mice and derived DCs with selective/supplemented media. Following harvest on d7, DCs were stimulated under estrogen-free conditions with loxoribine or CpG DNA for $18 \mathrm{~h}$. In DC cultures derived from WT mice, both the TLR7 and TLR9 ligands stimulated robust IL- 6 production, however, KIKO DC IL-6 production was significantly decreased. TLR stimulation increased IL-6 levels more than 20-fold in media from B6 WT DCs, with the stimulation index reduced by $\sim 50 \%$ in KIKO animals. These data indicate that ER $\alpha$ significantly modulates TLR7 and 9 responses by DCs via direct ERE binding on target genes.

\section{Discussion and Conclusion}

We previously reported that lupus prone ER $\alpha$ KO mice had significantly reduced renal disease and significantly prolonged survival [14]. We subsequently demonstrated that ER $\alpha$ modulates TLR signaling in both C57BL/ 6 and lupus prone mice (NZM2410 and MRL/lpr) [1]. The mechanism of ER $\alpha$ effect on TLR-induced inflammatory endpoints is currently unknown and is the focus of the current report. The major finding in this study is the requirement for ligand-independent ERE binding by ER $\alpha$ for robust stimulation of TLR-induced inflammatory endpoints.

It is well known that estrogen can modulate IL-6 gene expression [15,16]. Classically, this would occur via ER $\alpha$ binding to an estrogen response element (ERE). There is a growing evidence, however, that the molecular mechanisms, by which ER $\alpha$ exerts its effects, on IL- 6 and other target genes, are more complicated than the classic pathway of ligand-activated transcriptional activation. ER $\alpha$ also acts via multiple nonclassical signaling pathways to regulate cellular responses. For example, ER $\alpha$ may bind to other transcription factors such as AP- $1, \mathrm{C} / \mathrm{EBP} \beta$, and NFKB to regulate transcription of IL- 6 and others [17-22]. It is also possible that ER $\alpha$ exerts some of its effects by differentially recruiting co-activators or co-repressors, such as p300 to the transcriptional complex to impact gene expression depending on the cell type and environment $[23,24]$. This study provides additional evidence for ligand-independent actions of $E R \alpha$, since the experiments reported herein, were done under estrogen-free conditions. Our results were unexpected, however, in that we hypothesized the mechanism of ER $\alpha$ impact on TLR signaling would be both estrogen-independent and EREindependent. We speculated that the effect would be genomic, by ER $\alpha$ tethering to other transcription factors, but would not require direct DNA binding.

Similar to ER $\alpha \mathrm{KO}$ animals, however, IL-6 expression levels in response to TLR stimulation were significantly decreased in the setting of an ER $\alpha$ DNA binding mutant. This DNA binding domain mutant (NERKI) retains all other functions of ER $\alpha$, including tethering and ligand binding [2]. The mutant also retains the rapid action effects of cytoplasmic ER $\alpha$ (ex. MAPK signaling). If either of these ER $\alpha$ mechanisms were involved, we would have expected to see no change in TLR-stimulated IL- 6 production compared with WT levels. Again, all stimulation experiments were carried out under estrogen-free conditions, thus, despite the mutant having an intact ligand-binding domain, the effect was estrogen-independent. One caveat to this, however, is that estrogen is required for the normal development of immune cells such as DCs. This development also requires ER $\alpha$; as has been demonstrated by our experiments and other experimental works in the field $[1,13]$. Thus, cells are exposed to estrogen in vivo and during initial culture. There may be some threshold or triggering event dependent on estrogen that impacts (imprints on) future signaling (i.e. a developmental effect). Our results suggest that if imprinting on immune cell development is the underlying mechanism, then ERE binding by ER $\alpha$ is also required for immune cell development. Further work is needed with conditional knockout animals and/or in vitro knockdown experiments to determine whether the estrogen-independent effect of ER $\alpha$ on TLR signaling is absolute.

This study provides further evidence for a ligand-independent effect of ER $\alpha$ on TLR-induced gene expression in spleen cells and bone marrow-derived dendritic cells, which we have shown is ERE-dependent. Additional work is needed to elucidate the specific mediators of TLR signaling upstream of ERE binding by $E R \alpha$. Defining the molecular mechanism(s) of ER $\alpha$ effects on TLR signaling is critical to our understanding of female-predominant autoimmune diseases such as SLE and may lead to future therapies that target particular ER $\alpha$ actions and modulate innate immunity. 


\section{Acknowledgement}

We have been supported with the grant by South Carolina Clinical and Translational Research (SCTR) Institute, NIH Grant number UL1 TR000062, KL2 TR000060.

\section{References}

1. Cunningham MA, Naga OS, Eudaly JG, Scott JL, Gilkeson GS (2012) Estrogen receptor alpha modulates Toll-like receptor signaling in murine lupus. Clin Immunol 144(1): 1-12.

2. Sinkevicius KW, Burdette JE, Woloszyn K, Hewitt SC, Hamilton K, et al. (2008) An estrogen receptor-alpha knock-in mutation provides evidence of ligand-independent signaling and allows modulation of ligand-induced pathways in vivo. Endocrinology 149(6): 2970-2979.

3. Jakacka M, Ito M, Martinson F, Ishikawa T, Lee EJ, et al. (2002) An estrogen receptor (ER) alpha deoxyribonucleic acid-binding domain knock-in mutation provides evidence for nonclassical ER pathway signaling in vivo. Mol Endocrinol 16(10): 2188-2201.

4. Richards HB, Satoh M, Shaw M, Libert C, Poli V, Reeves WH (1998) Interleukin 6 dependence of anti-DNA antibody production: evidence for two pathways of autoantibody formation in pristane-induced lupus. J Exp Med 188(5): 985-90.

5. Ryffel B, Car BD, Gunn H, Roman D, Hiestand P, et al. (1994) Interleukin-6 exacerbates glomerulonephritis in (NZB $x$ NZW)F1 mice. Am J Pathol 144(5): 927-937.

6. Finck BK, Chan B, Wofsy D (1994) Interleukin 6 promotes murine lupus in NZB/NZW F1 mice. J Clin Invest 94(2): 585-591.

7. Mihara M, Takagi N, Takeda Y, Ohsugi Y (1998) IL-6 receptor blockage inhibits the onset of autoimmune kidney disease in NZB/W F1 mice. Clin Exp Immunol 112(3): 397-402.

8. Inaba K, Inaba M, Romani N, Aya H, Deguchi M, et al. (1992) Generation of large numbers of dendritic cells from mouse bone marrow cultures supplemented with granulocyte/macrophage colony-stimulating factor. J Exp Med 176(6): 1693-1702.

9. Carreras E, Turner S, Frank MB, Knowlton N, Osban J, et al. (2010) Estrogen receptor signaling promotes dendritic cell differentiation by increasing expression of the transcription factor IRF4. Blood 115(2): 238-246.

10. Carreras E, Turner S, Paharkova-Vatchkova V, Mao A, Dascher C, et al. (2008) acts directly on bone marrow myeloid progenitors to differentially regulate GM-CSF or Flt3 ligand-mediated dendritic cell differentiation. J Immunol 180(2): 727-738.

11. Kovats S, Carreras E (2008) Regulation of dendritic cell differentiation and function by estrogen receptor ligands. Cell Immunol 252(1-2): $81-$ 90.
12. Mao A, Paharkova-Vatchkova V, Hardy J, Miller MM, Kovats S (2005) Estrogen selectively promotes the differentiation of dendritic cells with characteristics of Langerhans cells. J Immunol 175(8): 51465151.

13. Paharkova-Vatchkova V, Maldonado R, Kovats S (2004 Estrogen preferentially promotes the differentiation of $\mathrm{CD} 11 \mathrm{c}+$ CD11b(intermediate) dendritic cells from bone marrow precursors. J Immunol 172(3): 1426-1436.

14. Svenson JL, EuDaly J, Ruiz P, Korach KS, Gilkeson GS (2008) Impact of estrogen receptor deficiency on disease expression in the NZM2410 lupus prone mouse. Clin Immunol 128(2): 259-268.

15. Jilka RL, Hangoc G, Girasole G, Passeri G, Williams DC, et al. (1992) Increased osteoclast development after estrogen loss: mediation by interleukin-6. Science 257(5066): 88-91

16. Ray A, Prefontaine KE, Ray P (1994) Down-modulation of interleukin-6 gene expression by 17 beta-estradiol in the absence of high affinity DNA binding by the estrogen receptor. J Biol Chem 269(17): 1294012946.

17. Biswas DK, Singh S, Shi Q, Pardee AB, Iglehart JD (2005) Crossroads of estrogen receptor and NF-kappaB signaling. Sci STKE 2005(288): pe27.

18. Jakacka M, Ito M, Weiss J, Chien PY, Gehm BD, Jameson JL (2001) Estrogen receptor binding to DNA is not required for its activity through the nonclassical AP1 pathway. J Biol Chem 276(17): 1361513621.

19. Safe S (2001) Transcriptional activation of genes by 17 beta-estradiol through estrogen receptor-Sp1 interactions. Vitam Horm 62: 231-252.

20. Ray P, Ghosh SK, Zhang DH, Ray A (1997) Repression of interleukin-6 gene expression by 17 beta-estradiol: inhibition of the DNA-binding activity of the transcription factors NF-IL6 and NF-kappa B by the estrogen receptor. FEBS Lett 409(1): 79-85.

21. Kurebayashi S, Miyashita Y, Hirose T, Kasayama S, Akira S, et al. (1997) Characterization of mechanisms of interleukin- 6 gene repression by estrogen receptor. J Steroid Biochem Mol Biol 60(1-2): 11-7.

22. Galien R, Garcia T (1997) Estrogen receptor impairs interleukin-6 expression by preventing protein binding on the NF-kappaB site. Nucleic Acids Res 25(12): 2424-2429.

23. Louthrenoo W, Kasitanon N, Sukitawut W, Wichainun R (2003) A clinical study of crystal-proven gouty arthritis in a university hospital. J Med Assoc Thai 86(9): 868-875.

24. Louthrenoo W, Kasitanon N, Mahanuphab P, Bhoopat L, Thongprasert S (2003) Kaposi's sarcoma in rheumatic diseases. Semin Arthritis Rheum 32(5): 326-333. 